\title{
TROPAS DE PRETOS E PARDOS EM MINAS GERAIS: O RECRUTAMENTO PARA A GUERRA LUSO-CASTELHANA (1766-1780)
}

\author{
Leandro Francisco de Paula \\ Orientação: Luiz Geraldo Silva
}

PALAVRAS-CHAVE: reformismo ilustrado, mobilização militar, tropas de pretos e pardos.

A segunda metade do século XVIII foi marcada por reformas de cunho ilustrado implementadas nas regiões dominadas pela coroa portuguesa. Entre essas medidas, estavam aquelas destinadas ao aprimoramento do aparato militar português. A reestruturação militar de Portugal e de seus domínios na América se tornou necessária após 1756, quando Inglaterra e França, rivais de longa data, iniciaram uma luta armada posteriormente denominada de Guerra dos Sete Anos. ${ }^{1}$ A Espanha era a aliada da França no conflito. Já Portugal, como sempre, havia adotado uma política de neutralidade, até ser pressionado pela Inglaterra a entrar na guerra, quando esta se encontrava próxima ao fim. O adversário mais direto de Portugal nessa disputa bélica era a própria Espanha. ${ }^{2}$ Em 1762, França e Espanha invadiram Portugal. Como havia uma precariedade do aparato defensivo lusitano, a coroa teve de pedir auxílio ao seu aliado principal: a Inglaterra. Por esse motivo, a hostilidade fronteiriça foi curta. Porém, o conflito serviu para explicitar a questão da fragilidade defensiva de Portugal. Era preciso ser feita uma reforma

\footnotetext{
${ }^{1}$ MELLO, Christiane F. Pagano de . A Guerra e o Pacto. A política de intensa mobilização militar nas Minas Gerais.. In: CASTRO, Celso; IZECKSOHN, Vitor; KRAAY, Hendrik. (Org.). A Nova História Militar Brasileira. Rio de Janeito: FGV / Bom Texto, 2004, v. , p. 69; MAXWELL, K. op. cit., p. 119-122; ALDEN, Dauril. Royal Government in Colonial Brazil - with special reference to the administration of the marquis of Lavradio, viceroy, 1769-1779. Berkeley/Los Angeles, 1968, p. 96-99.

${ }^{2}$ MELLO, C. F. P. de. op. cit., p. 70.
} 
militar com urgência. Para isso, Pombal contratou Conde de Lippe, um ilustrado e muito experiente militar de origem alemã, o qual se encontrava naquele momento a serviço da Inglaterra. ${ }^{3} \mathrm{O}$ conflito entre esses dois reinos no próprio continente europeu incendiou, por sua vez, as questões relativas às fronteiras meridionais da América portuguesa, região disputada por ambas as coroas desde as últimas décadas do século XVII.

Desde a fundação da Colônia de Sacramento, em 1680, situada na margem do Rio da Prata, os conflitos entre Portugal e Espanha nas fronteiras meridionais foram relativamente constantes. ${ }^{4}$ O Tratado de Limites, o qual foi assinado em Madrid em 1750, tinha o objetivo de amenizar tais conflitos territoriais entre os dois reinos. Por problemas internos aos territórios disputados e dificuldades de demarcação de fronteiras, o compromisso não obteve êxito. $\mathrm{O}$ Tratado de El Pardo, assinado em 1761, deu fim aos acordos selados naquele documento de $1750 .^{5}$

Se a contenda de 1762-1763 foi breve no território europeu, na América ela se estendeu por vários anos. Em 1763, D. Pedro de Cevallos, comandante das forças espanholas, invadiu a Colônia de Sacramento, os fortes de São Miguel e de Santa Tereza, e o Rio Grande de São Pedro. Era o início do denominado período de dominação espanhola no sul da América portuguesa, o qual se prolongou até $1776 .{ }^{6}$ Esses fatores contribuíram para que a década de 1760 fosse de intensa mobilização e reestruturação do aparato defensivo do Estado do Brasil.

A primeira medida de Pombal visando a defesa da América portuguesa foi a transferência da capital do vice-reino de Salvador

\footnotetext{
${ }^{3}$ MAXWELL, K.. op. cit., p. 119-123.

${ }^{4}$ POSSAMAI, Paulo César. A Colônia do Sacramento, o "jardim da América". Estudos Ibero-Americanos. Porto Alegre : PUCRS, v. 30, n. 1, p. 33-46, jun./2004, p. 40-41.
${ }^{5}$ ALDEN, Dauril. op. cit., p. 86-96.
${ }^{6} \mathrm{KÜHN}$, Fábio. A fronteira em movimento: relações luso-castelhanas na segunda metade do século XVIII. Estudos Ibero-Americanos. Porto Alegre : PUCRS, v.XXV, n.2, pp. 91-112, dez./1999, p. 91.


para o Rio de Janeiro, em 1763. A região Centro-Sul se tornaria, assim, o centro de comando defensivo do Estado do Brasil. Como estava situada mais próxima ao palco da guerra, seria mais eficaz na defesa de qualquer ataque vindo daquela direção, bem como seria mais fácil mobilizar tropas no conjunto da América portuguesa. Outra medida foi o envio de dois aristocratas ilustrados e aliados ao serviço das armas ao Estado do Brasil: o morgado de Mateus, nomeado governador da capitania de São Paulo, a qual foi restabelecida em 1765; e o marquês do Lavradio, o qual havia sido governador da Bahia em 1768. Este fora, então, nomeado vice-rei em 1769. Lavradio também teria a função de governador e capitãogeneral da capitania do Rio de Janeiro. ${ }^{7}$ Sem dúvida, seu nome foi o mais forte na tarefa de reestruturação defensiva e militar de toda a América portuguesa, na década de 1770 , assim como no conflito luso-castelhano nas fronteiras meridionais. $\mathrm{O}$ vice-rei foi $\mathrm{o}$ responsável por uma ampla reformulação do tabuleiro políticoadministrativo do Estado do Brasil. Como sua função principal naquele momento era a de exercer o comando na mencionada guerra, impôs ao marquês de Pombal a condição de recomendar experientes militares nos governos de diversas capitanias. Essa imposição foi aceita instantaneamente pelo ministro de Portugal. Entre esses governadores recomendados por Lavradio, estava aquele que seria o responsável pela reestruturação militar da capitania de Minas Gerais: Dom Antonio de Noronha.

Noronha assumiu o posto de governador de Minas em 1774. A constante ameaça de uma guerra de grandes proporções fez com que a coroa ordenasse aos governadores das diversas capitanias da América portuguesa que formassem corpos militares entre todas as camadas sociais; Dentre estas, estavam aquelas constituídas por indivíduos de cor. Essa ordem já estava presente na Carta Régia enviada em 1766 a todos os governadores do Estado do Brasil. Neste documento determinava-se o alistamento em corpos militares de todos os indivíduos aptos a exercerem o serviço das armas, "sem

${ }^{7}$ ALDEN, op. cit., p. 13-28; MAXWELL, op. cit., p. 126. 
exceção de Nobres, Plebeus, Brancos, Mestiços, Pretos, Ingênuos e Libertos". ${ }^{8}$ Logo que chegou em Minas Gerais, Noronha tratou de cumprir com essas exigências, reestruturando os corpos militares existentes na capitania, incluindo aqueles formados por homens de cor, além de iniciar uma intensa atividade de recrutamento militar. É importante ressaltar que na capitania em questão se fixara desde meados do século XVIII a maior população de cativos da América portuguesa, bem como esta possuía um imenso contingente populacional composto por indivíduos livres de cor. As relações entre o conflito luso-castelhano nas partes meridionais da América portuguesa, a mobilização e o recrutamento militar de homens de cor em Minas Gerais, são os pontos principais de nosso trabalho.

Para tanto, analisamos fontes presentes no Arquivo Histórico Ultramarino - disponíveis através do Projeto Resgate; a coleção Documentos Interessantes Para a História e Costumes de São Paulo; Século XVIII, século Pombalino do Brasil, coleção de Marcos Carneiro de Mendonça; Cartas do Rio de Janeiro (1769-1776), do Marquês do Lavradio, impressas pelo Instituto Estadual do Livro do Rio de Janeiro em 1978; e a Instrução para o Governo da Capitania de Minas Gerais (1780), da autoria de João José Teixeira Coelho, impressa em 1994 pela Fundação João Pinheiro de Belo Horizonte, pertencente ao conjunto de documentos impressos da Coleção Mineiriana.

O trabalho foi dividido em três capítulos. No primeiro, procuramos enfatizar o quadro geral que possibilitou a intensa mobilização militar no Estado do Brasil. No segundo, se destacou a reestruturação militar na capitania de Minas Gerais na década de 1770 e a presença de homens de cor nesses corpos militares reestruturados. No terceiro capítulo, ressaltamos o impacto das

\footnotetext{
${ }^{8}$ Cf. Carta régia de D. José, ordenando ao Conde da Cunha, vice-rei do Brasil, para que mande alistar, sem exceção, todos os moradores em estado de poderem servir nas Tropas Auxiliares e Ordenanças de Cavalaria e Infantaria. AHU-MG, cx. 85, doc. 42. Lisboa, 22 de março de 1766.
} 
mencionadas reformas militares na capitania, bem como a prática de recrutamento e o envio de pretos e pardos para a região de conflito.

No decorrer da pesquisa ficou claro que a mecânica da formação, institucionalização e recrutamento de indivíduos de cor nas diversas capitanias do Estado do Brasil, na segunda metade do século XVIII, tinha relação direta com a dinâmica da escravidão em cada capitania específica e com a presença cotidiana de indivíduos de cor nas inúmeras funções sociais destinadas a eles no interior de cada uma delas. No caso de Minas Gerais, por exemplo, nesse período, mesmo com uma grande resistência social, não se descartou a possibilidade de utilização de escravos em corpos militares, caso a mencionada guerra tomasse maiores proporções. No entanto, o que merece destaque é o envio de 4 mil recrutas para o palco do conflito em 1777: pressionado por Lavradio, Noronha foi obrigado a aprontar esse contingente às pressas, e os fazer marchar para o sul.

Uma grande expectativa foi construída com relação a essa tropa. Acreditava-se que iria reforçar enormemente as forças do lado português. Contudo, o que se viu foi um desastre: a começar pelo problema de abastecimento, pois os capitães-mores queixavam-se que não tinham comida nem para alimentar os próprios soldados regulares. ${ }^{9}$ Como resultado, a fome dos respectivos recrutas de Minas tornou-se tão generalizada a ponto de estes homens, quando se encontravam na região de Araçarigoama, chegarem a arrombar a porta de um armazém e roubarem os mantimentos lá existentes. ${ }^{10}$ Entretanto, a falta de alimentos não era o único problema com relação a dita tropa: a deserção também era grande, de modo que Martim Lopes Lobo de Saldanha (1775-1782), o então governador de São Paulo e comandante das tropas no sul, ordenou que os capitães-mores caçassem e prendessem os desertores, os quais seriam

9 Cf. Para o Sargento Mor Lucas de Siqueira Franco, da Atibaya. DI. Vol. LXXVIII, p. 48. São Paulo, 12 de abril de 1777.

${ }^{10}$ Cf. Para o Sargento Mor Antonio Correya de Lemos Leite, de Parnaiba. DI. Vol. LXXVIII, p. 136. São Paulo, 5 de maio de 1777. 
castigados para dar exemplo aos demais. ${ }^{11}$ Finalmente, em junho de 1777, Lavradio tomou conhecimento da qualidade desses recrutas de Minas Gerais. Segundo a descrição de Saldanha, era uma multidão composta, em sua maioria, de negros, que se encontravam, "inteiramente nus, sem mais que umas ceroulas e camisas, com muitas poucas armas particulares, e estas desconcertadas". ${ }^{12}$ Segundo o governador de São Paulo, seria "mais proveitoso ao Real Serviço fazê-las retroceder do que infestar a campanha do sul, com um troço de gente quase inútil para o ministério da guerra". ${ }^{13}$ O vice-rei ordenou, então, o retorno da tropa para Minas. Isso, porém, não foi menos dificultoso, pois se já havia o problema da falta de alimentos destinados a esses indivíduos quando eles ainda saíam da capitania em questão em direção à região do conflito, no retorno não foi diferente.

Por fim, questões como a da ascensão social de pretos e pardos nos corpos militares; utilização de escravos no emprego das armas; relações entre os indivíduos que pertenciam a essas tropas com outras instituições, dentre outras discussões possíveis, só serão melhor entendidas com o aprofundamento e extensão dessa pesquisa na pós-graduação.

${ }^{11}$ Cf. Para o Sargento Mor Antonio Pacheco da Silva, de Itu. DI. Vol. LXXVIII, p. . São Paulo, 12 de maio de 1777.

${ }_{12}$ ALDEN, op. cit., p. 250.

${ }^{13}$ Cf. Para o Capitão Mor Antonio Correya Pinto, das Lages. DI. Vol. LXXVIII, p. 204. São Paulo, 2 de junho de 1777. 